05.1

\title{
Накопление повреждений при статическом деформировании твердого тела регулярного строения: микротрещины, неотрелаксированные напряжения
}

\author{
(C) А.М. Лексовский ${ }^{1}$, Б.Л. Баскин ${ }^{1}$, Г.Н. Губанова ${ }^{2}$, В.Е. Юдин ${ }^{2}$ \\ ${ }^{1}$ Физико-технический институт им. А.Ф. Иоффре РАН, Санкт-Петербург, Россия \\ ${ }^{2}$ Институт высокомолекулярных соединений РАН, Санкт-Петербург, Россия \\ E-mail: albert.leksowskij@mail.ioffe.ru
}

Поступило в Редакцию 20 августа 2020г.

В окончательной редакции 9 сентября 2020 г.

Принято к публикации 9 сентября 2020г.

Методами акустической эмиссии в варианте линейной локации и внутреннего трения показано, что при растяжении изначально равновесной композиции типа углепластик в местах взрывообразного рождения микротрещин накапливаются неотрелаксированные напряжения. Это обусловлено неполной завершенностью релаксационного перераспределения накопленной энергии/упругой деформации по нелинейному механизму. Повышающийся уровень неотрелаксированных напряжений неизбежно переводит гетерогенное тело в метастабильное состояние. Вследствие этого сокращается диссипативная способность системы в целом и увеличивается вероятность возникновения неравновесной трещины.

Ключевые слова: микротрещины, акустическая эмиссия, внутреннее трение, нелинейное перераспределение, неотрелаксированные напряжения, метастабильное состояние.

DOI: 10.21883/PJTF.2020.23.50351.18521

В твердом теле под нагрузкой, как известно, имеет место процесс накопления микроструктурных изменений разного масштабного уровня $[1,2]$, сопровождающийся, в частности, деградацией пластических и ряда других служебных свойств. Микро- и мезотрещины традиционно считаются ярко выраженными деструктивными элементами поврежденности (см., например, [3]). Однако не все так однозначно. Так, данные растровой электронной микроскопии (РЭМ) in situ [4] и исследование деформации с помощью прецизионной интерферометрической методики [5] показывают, что рождение микротрещины представляет собой акт дискретной/взрывной локальной пластической деформации, скорость изменения которой может на несколько порядков превышать актуальную скорость ползучести. Диссипативные свойства материала влияют на развитие релаксационного перераспределения накопленной энергии/упругой деформации по нелинейному механизму и на размер микротрещины. В настоящей работе рассматривается вопрос о роли накопления микротрещин и увеличения неотрелаксированных напряжений вследствие микроструктурных изменений в процессе деградации гетерогенного твердого тела при статическом растяжении.

Объектом изучения являлся углепластик/микропластик (УП) с одноосным армированием на основе угольной ленты ЭЛУР-ПО.1 и связующего ЭДТ-10. Углеродное волокно: прочность $\sigma_{B}=2.5 \mathrm{GPa}$, модуль Юнга $E=225 \mathrm{GPa}$, разрывная деформация $\varepsilon_{B}=1.1-1.3 \%$, диаметр элементарного волокна $\sim 8-9 \mu \mathrm{m}$. Матрица: прочность $\sigma_{B}=70-90 \mathrm{MPa}$, модуль сдвига $E_{\text {shear }}=0.95-1.1 \mathrm{GPa}$, разрывная деформация
$\varepsilon_{B}=6-8 \%$. Образцы УП для механических испытаний растяжением имели размеры $160 \times 10 \times(0.3-1) \mathrm{mm}$. Объемное содержание углеродных волокон $V_{f} \sim 60 \%$. Образцы УП выдерживались при температуре $160^{\circ} \mathrm{C}$ в течение 3-6h и охлаждались при давлении $10 \mathrm{~Pa}$. Для изучения изменения диссипативных свойств, а именно температурного сдвига максимума модуля механических потерь $\operatorname{tg} \delta\left(T_{M}\right)$, использовался обратный крутильный маятник МК-002 разработки ИВС РАН [6]. Для регистрации сигналов акустической эмиссии (АЭ) применялась аппаратура на базе микро-ЭВМ ,Электроника-60“ и РСНР 9835 А разработки ИАЭ им. И.В. Курчатова [7]. Использовались резонансные пьезодатчики с $f_{r}=450 \mathrm{kHz}$. Уровень шумов не более $3 \mu \mathrm{V}$. Динамический диапазон не хуже $60 \mathrm{~dB}$, полоса частот $0.1-1.1 \mathrm{MHz}$, неравномерность амплитудно-частотной характеристики $\pm 3 \mathrm{~dB}$.

Регистрация сигналов АЭ от разрывов волокон по длине образца дает возможность определить участки УП с разной активностью разрывов волокон и оценить изменение вязкоупругих свойств матрицы на этом участке с помощью метода крутильного маятника. Для этого полоска УП размером $100 \times 25 \times 0.4 \mathrm{~mm}$ нагружалась на разрывной машине $1958 \mathrm{У}-10-1$ до $\sim 0.9 \sigma_{B}$ и из областей с минимальной и максимальной активностью АЭ вырезались образцы размером $25 \times 5 \times 0.4 \mathrm{~mm}$ для крутильного маятника. Ориентация вырезанных образцов - вдоль волокон. Такой размер образцов позволял исключить эффекты, связанные с деформацией объема матрицы при кручении углепластика. Точность определения температуры $T_{M}$ УП, близкой, как показано в [6], 

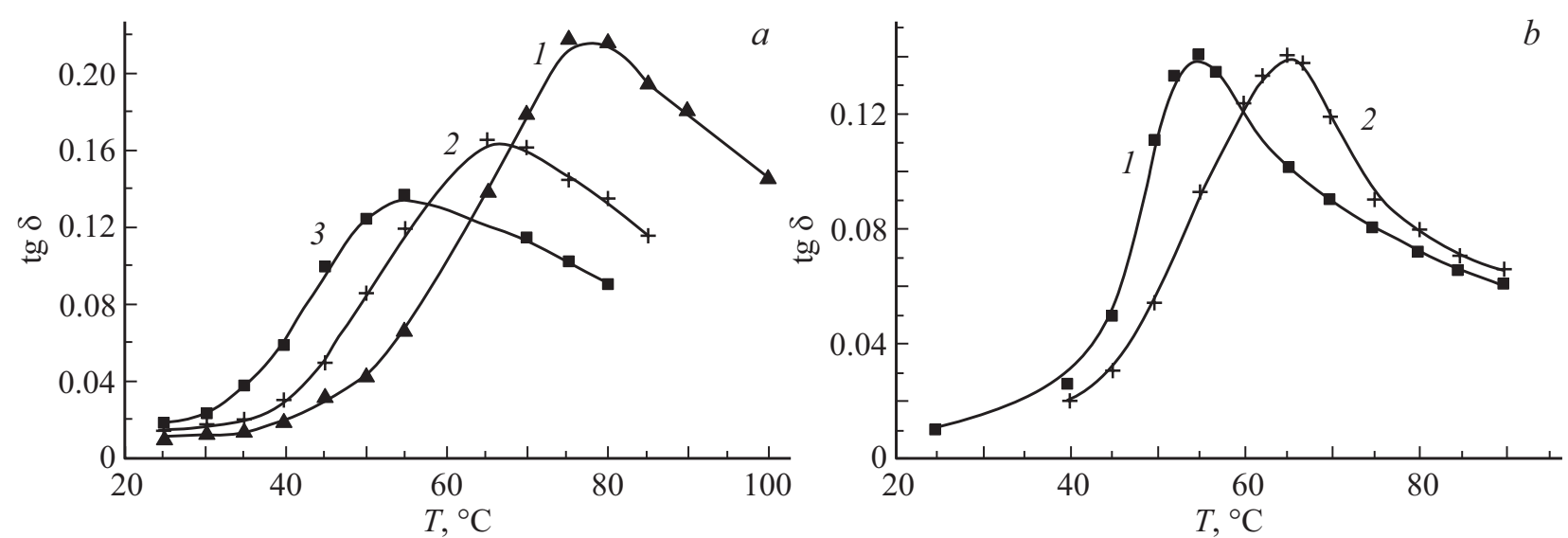

Рис. 1. Температурные зависимости тангенса угла механических потерь $(\operatorname{tg} \delta$ ) углепластика. $a) 1-$ исходное (равновесное) состояние; недеформированный образец (выдержка при температуре $160^{\circ} \mathrm{C}$ в течение $3-6 \mathrm{~h}$ и охлаждение при давлении 10 Ра); 2 - образец из пассивной зоны АЭ; 3 - образец из активной зоны АЭ. $b$ ) образец из зоны множественного образования микротрещин: 1 - до отжига; 2 - после отжига при $100^{\circ} \mathrm{C}$ в течение $1 \mathrm{~h}$.

к $T_{G}$ (температура стеклования) чистого связующего в блоке, составляла $2-3^{\circ} \mathrm{C}$.

Быстрое охлаждение образцов УП (1-2 min) приводит к возникновению значительных остаточных напряжений, что вызывает сдвиг максимума $\operatorname{tg} \delta\left(T_{M}\right)$ в сторону низких температур на $\sim 15^{\circ} \mathrm{C}$ по сравнению со случаем медленного охлаждения $(2-3 \mathrm{~h})$. Образцы перед механическими испытаниями отжигались в течение $1 \mathrm{~h}$ при $100^{\circ} \mathrm{C}$ (для ЭДТ-10 $T_{G}=85^{\circ} \mathrm{C}$ ) и медленно охлаждались. После отжига вязкоупругий спектр матрицы становился подобным спектру связующего в блоке. Образцы для крутильного маятника вырезались как из исходных (ненагружавшихся), так и из образцов после деформирования растяжением.

Из данных рис. 1,a можно видеть, что наибольшее смещение максимума температурной зависимости $\operatorname{tg} \delta(T)$ в сторону меньших температур по сравнению с таковым для изначально равновесного (ненагруженного) состояния (кривая 1) характерно для образца из области с наибольшей АЭ-активностью (кривая 3). Наблюдаемое на рис. 1 снижение $T_{M}$ углепластика в процессе его деформирования в основном связано с повышением концентрации сдвиговых напряжений от разрывов волокон из-за пластической деформации при образовании микропустот в матрице. В этой ситуации можно ожидать частичного восстановления вязкоупругого спектра $\operatorname{tg} \delta(T)$ углепластика при его отжиге выше $T_{G}$ связующего. Действительно, нагрев образцов углепластика из активной и пассивной зон приводит к восстановлению их $T_{M}$ почти до $T_{M}$ ненагруженного образца. На рис. $1, b$ приведен пример восстановления спектра $\operatorname{tg} \delta(T)$ для образца из зоны наиболее активного разрушения волокон: $T_{M}$ сдвигается в сторону высоких температур на $\geqslant 10^{\circ} \mathrm{C}$, но не до уровня $T_{M} \approx 75-78^{\circ} \mathrm{C}$ для исходного состояния (рис. $1, a$, кривая 1 ), т. е. в области активного разрушения волокон еще остались неотрелаксированные напряжения. В таком случае отжиг выше $T_{G}$ связующего после первого деформирования может восстановить ре- лаксационные свойства матрицы в более поврежденных областях и изменить кинетику задержанного разрушения в целом при повторном нагружении.

Были проведены следующие опыты. Образцы углепластика были разделены на три серии (по пять образцов в каждой). Первая серия образцов разрушалась полностью за один раз (однократное нагружение, рис. 2, a). Образцы второй серии (рис. $2, b)$ нагружались до $\sim 0.9 \sigma_{B}$, затем полностью разгружались и далее вновь (без отдыха) нагружались вплоть до разрыва. Можно видеть, что прежней АЭ-активности вплоть до уровня предыдущего деформирования не наблюдается. Это известный эффект Кайзера, когда предварительным нагружением провоцируется срабатывание „всех“ концентраторов, включая пузырьки, поры и др. Этим превентивным способом можно определить границы „безопасного“ деформирования. Итак, в результате первого нагружения в образце накопилось некоторое количество микротрещин размером порядка структурного элемента $(\sim 20 \mu \mathrm{m})$ и в этих областях появились неотрелаксированные напряжения (рис. $1, b)$. Образцы третьей серии (рис. 2,c) также доводились до $0.9 \sigma_{B}$, разгружались, и только после прогрева при $100^{\circ} \mathrm{C}\left(\right.$ выше $\left.T_{G}\right)$ в течение $1 \mathrm{~h}$ следовало повторное деформирование до полного разрушения. Можно было ожидать существенного изменения АЭ-рельефа в области до $0.9 \sigma_{B}$ в связи с улучшением диссипативных свойств и соответственно улучшения деформационных свойств в целом. На заключительной стадии нагружения АЭ-картина должна оставаться подобной прежней, но при большем значении конечной деформации. В самом деле, для образцов третьей серии характерным является восстановление активности разрыва волокон при повторном нагружении практически с самого начала и увеличение продолжительности деформирования. Процесс разрыва волокон при повторном нагружении в образцах этой серии идет более активно, причем уже в других зонах образца. При этом после $0.9 \sigma_{B}$ наиболее активной может стать зона соседняя с зоной 

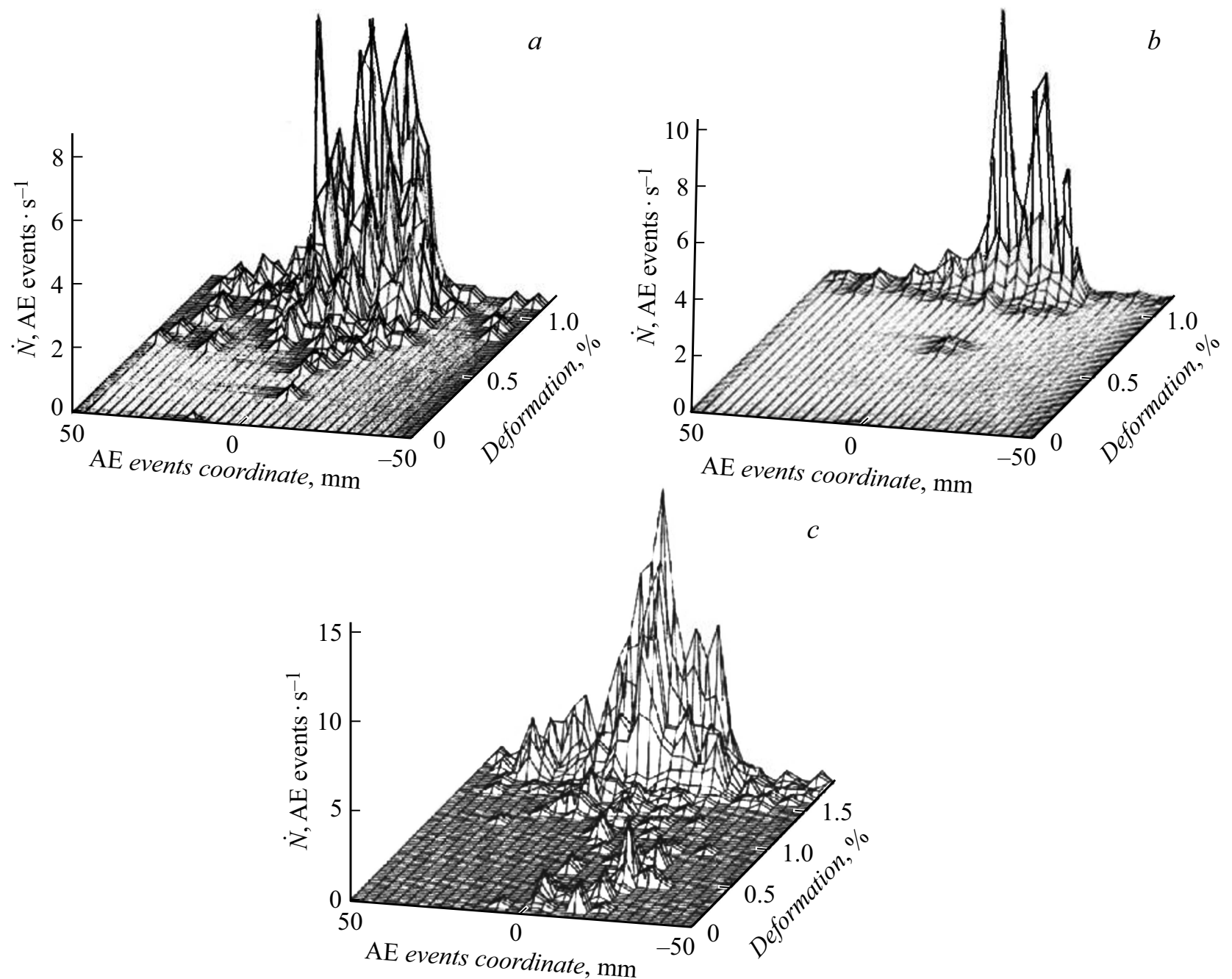

Рис. 2. Изменение скорости накопления микротрещин по длине образца углепластика в процессе его деформирования. $a-$ из первой серии (исходное состояние); $b-$ из второй серии: после предварительного нагружения до $\sim 0.9 \sigma_{B}$, полной разгрузки и последующего (без отдыха) растяжения вплоть до разрыва; $c$ - из третьей серии: после предварительного нагружения до $\sim 0.9 \sigma_{B}$, полной разгрузки и прогрева при $100^{\circ} \mathrm{C}$ в течение $1 \mathrm{~h}$ и последующего повторного деформирования вплоть до разрыва.

АЭ-активности при первом деформировании. В условиях совместности деформирования в процесс включаются соседние, еще неповрежденные области [8]. Естественным следствием этого являются возрастание активности менее дефектных участков композита и повышение его прочности при повторном нагружении. Действительно, средняя прочность углепластика на основе ЭДТ-10, равная $870 \pm 30 \mathrm{MPa} \mathrm{в} \mathrm{исходном} \mathrm{состоянии,} \mathrm{повышается}$ после предварительного нагружения и последующего отжига до $\sim 1040 \pm 20 \mathrm{MPa}$ (на $19.5 \%$ ), несмотря на появление в композите множества повреждений в виде большого числа дефектов сплошности в районе разрывов волокон, т. е. трещин размером порядка структурного элемента.

Ранее [9] при исследовании поврежденности теплостойкой роторной стали $\mathrm{Cr}-\mathrm{Mo}-\mathrm{V}$ методами АЭ и рентгеновской дифрактометрии было показано, что наблюдаемая деградация пластичности вследствие более чем двадцатилетней эксплуатации обусловлена увеличе- нием микроискажений кристаллической решетки, плотности дислокаций и размеров блоков мозаики. Наибольшее изменение этих микроструктурных характеристик и соответственно более высокий уровень неотрелаксированных напряжений по сравнению с исходным состоянием отмечены для материала той части ротора, которая работала не при $510^{\circ} \mathrm{C}$, а при $300^{\circ} \mathrm{C}$. Увеличение напряжений второго рода ускоряет образование АЭкластеров - областей локальной взрывной пластической деформации, что увеличивает вероятность перехода гетерогенного тела в метастабильное состояние.

Представляется возможным сформулировать основной тезис: рост латентной энергии неотвратимо ведет к сокращению диссипативных свойств. В этом можно убедиться на примере развития единичной микротрещины в зоне процесса в условиях динамично растущей латентной энергии в данной области. На рис. 3 представлены РЭМ-данные in situ [4] динамики развития процесса в вершинной области магистральной трещины в образце 


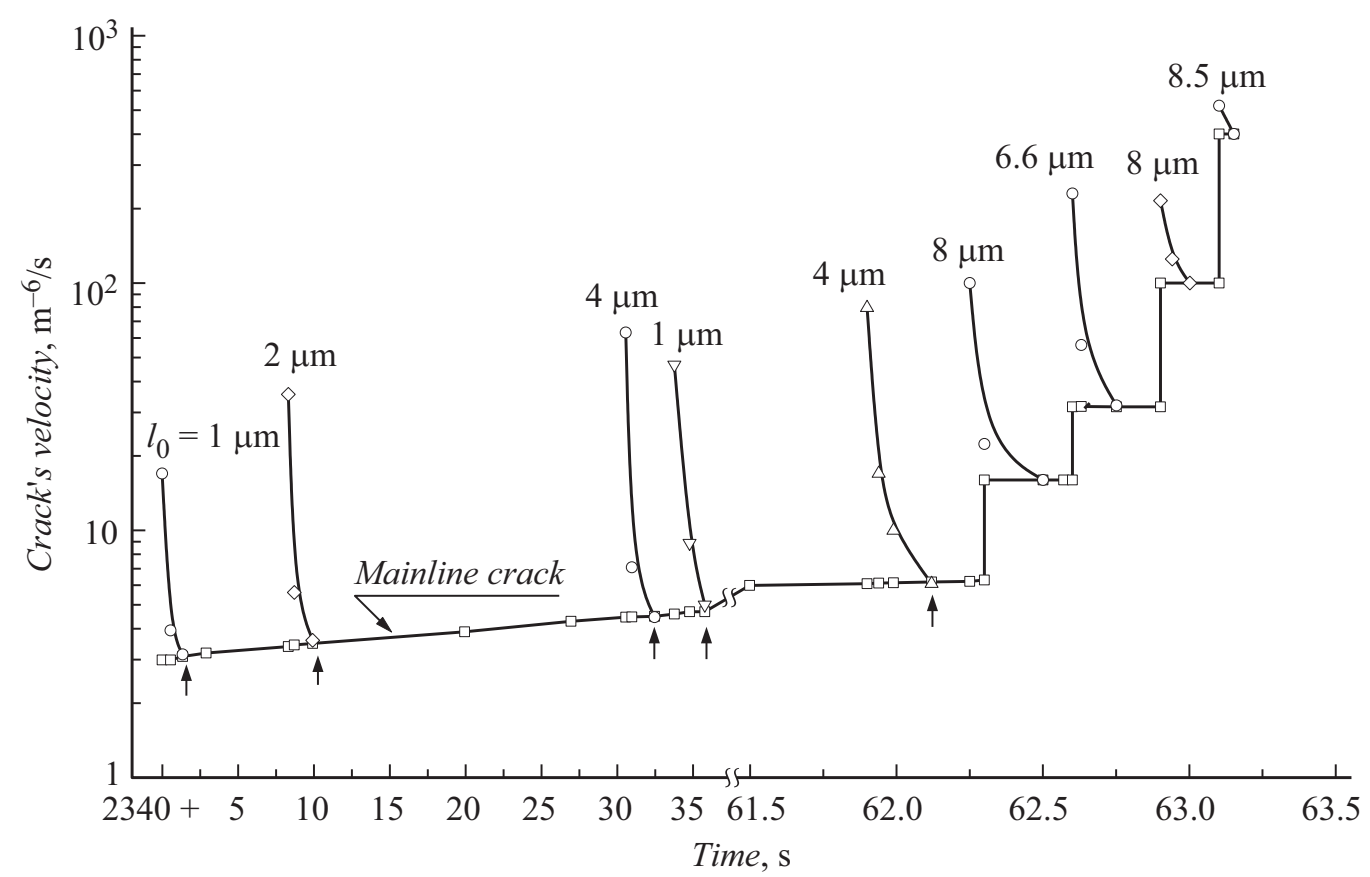

Рис. 3. Динамика изменения скорости роста микротрещин на релаксационной ветви их развития в зоне процесса ускоряющейся магистральной трещины на заключительном этапе ее „стационарного“ (докритического) роста.

из эпоксидной смолы типа ЭДТ-10. Эти данные позволяют сравнить длину релаксационной ветви скорости микротрещин после их взрывообразного рождения на заключительном этапе „стационарного“ развития магистральной трещины. Логарифмический масштаб отображения дает наглядное свидетельство последовательного дискретного сокращения релаксационной ветви скорости микротрещин в условиях растущей латентной энергии.

Итак, как показано выше, при статическом растяжении гетерогенной системы регулярного строения типа углепластик возникают области интенсивного взрывообразного рождения микротрещин. Именно в этих местах происходит накопление неотрелаксированных напряжений, что обусловлено неполной завершенностью релаксационного перераспределения запасенной энергии/упругой деформации по нелинейному механизму, вследствие чего сокращается диссипативная способность системы в целом. Естественно, повышающийся уровень неотрелаксированных напряжений неизбежно переводит гетерогенное тело в метастабильное состояние. По нашему мнению, влияние возрастающих внутренних, неотрелаксированных напряжений как основополагающего фактора поврежденности в общем случае заключается в сокращении глубины релаксации взрывной локальной пластической деформации по нелинейному механизму. Критичность напряженнодеформационного состояния определяется отнюдь не концентрацией микро- и мезотрещин, а динамическим соотношением между освобождаемой энергией в дискретном акте структурной перестройки и диссипативными свойствами ближайшего окружения или системы в целом.

\section{Конфликт интересов}

Авторы заявляют, что у них нет конфликта интересов.

\section{Список литературы}

[1] Панин В.Е., Лихачев В.А., Гриняев Ю.В. Структурные уровни деформации твердых тел. Новосибирск: Наука, 1985. $230 \mathrm{c}$.

[2] Шиейзман В.В., Якушев П.Н. // ФТТ. 2019. Т. 61. В. 7. C. 1298-1304. DOI: 10.21883/FTT.2019.07.47841.377

[3] Макаров П.В. // Физ. мезомеханика. 2010. Т. 13. В. 5. С. 97 112.

[4] Лексовский А.М., Баскин Б.Л. // ФТТ. 2011. Т. 53. В. 6. C. $1157-1168$.

[5] Лексовский А.М., Баскин Б.Л., Якушев П.Н. // ЖТФ. 2015. T. 85. В. 12. C. $153-155$.

[6] Кенунен И.В., Володин В.П. // Завод. лаб. 1990. № 5. С. 76 79.

[7] Ефремов М.И., Ржевкин В.Р., Тарараксин С.И., Чернов В.И. // Акустическая эмиссия материалов и конструкций. Ростов н/Д, 1984. Ч. 1. С. 139-140.

[8] Лексовский А.М., Абдуманонов А., Баскин Б.Л., Тиикин А.П. // ФТТ. 2013. Т. 55. В. 12. С. 2392-2397.

[9] Лексовский А.М., Агапов Ю.С., Исаев С.Н., Баскин Б.Л. // Письма в ЖТФ. 2018. Т. 44. В. 23. С. 46-51. DOI: 10.21883/PJTF.2018.23.47008.17470 